\title{
Investigation on the Wear Properties of Ti/TiC/TiN Composite Coatings Prepared by Powder Cored Wires Through TIG Method at Nitrogen Atmosphere on Titanium Substrate
}

\author{
Amir Hossein Kokabi ${ }^{a}$, Ali Ammari Allahyari ${ }^{b *}$ *i) \\ ${ }^{a}$ Department of Materials Science and Engineering, Sharif University of Technology, Azadi St. Tehran, \\ Iran \\ ${ }^{b}$ Department of Materials Science, School of Science and Engineering, Sharif University of Technology, \\ International Campus-Kish Island, Tehran, Iran
}

Received: September 06, 2018; Revised: December 23, 2018; Accepted: February 03, 2019

In this present study, Tungsten Inert Gas (TIG) welding and powder filled cored wires with nitrogen shielding gas were utilized to produce $\mathrm{TiC}$ and $\mathrm{TiN}$ surface composite coatings on the titanium (Ti) sheet substrate. The TIG procedure was done at same welding parameters for all of prepared samples. Phase analysis and microstructures were done by X-ray Diffraction (XRD), Energy-Dispersive X-ray Spectroscopy (EDS), Optical Microscopy (OM) and Scanning Electron Microscopy (SEM). The obtained results from XRD and EDS demonstrated that the presence of crystalline phases of TiC, TiN and Ti. SEM and OM exhibited formation of the spherical and dendritic TiC particles in a martensitic matrix and also, TiN pinhole areas with rough and collapsed arms. Maximum microhardness value obtained was $571 \mathrm{HV}$ in the case of sample treated with $\mathrm{TiC}$ cored wire at $95 \%$ argon $+5 \%$ nitrogen atmosphere. The Pin-on-disk wear tests showed that the coating with maximum hardness had a higher wear resistance due to the presence of fine and hard $\mathrm{TiC}$ particles in the high-impact toughness titanium alloy with uniform distribution.

Keywords: Tungsten Inert Gas, Wear Properties, Composite Coatings, Welding.

\section{Introduction}

Titanium and its alloys have been considered strongly in chemical, marine, aeronautical and medicine applications due to unique properties such as high strength and corrosion resistance, proper oxidation temperature and bio compatibility ${ }^{1}$. Beside these good properties, high friction coefficient, low hardness and wear resistance limits titanium alloys applications ${ }^{2-5}$.

Many techniques such as physical (PVD) and chemical (CVD) vapor deposition ${ }^{6-8}$, thermal and plasma spray ${ }^{9-12}$, laser cladding ${ }^{13-15}$ and electron beam processing ${ }^{16-18}$ have been used to improve wear properties of these alloys. Each of these processes deals with special advantages/disadvantages which make them a branch to study by researchers. Among of these, Gas Tungsten Arc (GTA) cladding as an arc welding procedure has considerable advantages compared with other methods such as simple and reachable instrument, nonoxidation process, simple operation and low cost. Therefore, high quality of clad layer can be attained by GTA cladding which makes it as potential technique to be used for surface modification by reinforcing technique ${ }^{19}$.

Ceramic powders-filled core wires have been used to improve surface properties such as hardness, wear and corrosion resistant, anti-erosion and other performance coatings by Tungsten Inert Gas (TIG) procedure ${ }^{3,20}$. In comparison to other fabricated procedures, TIG process has

*e-mail: ammari_allahyari@yahoo.com. advantages such as uniform distribution of reinforcement finer reinforcement particle size and clear interface ${ }^{21,22}$.

TiC can be considered as proper choice to used as cladding materials because of its enhanced properties, such as good thermal and chemical stabilities, high melting point, hardness and Young's modulus ${ }^{23}$.

Applying nitrogen atmosphere form new composition during GTA-based processes especially in the case of reactive staring wires. Some works have been investigated the $\mathrm{TiC}$ and TiN formation through GTA cladding procedure, separately. In this research, TiC/TiN composite hard coatings were applied on the commercial pure titanium (CP-Ti) by TIG process. The main purpose of this present work characterizes of TiC-TiN composite coatings formation through GTA cladding and investigation of its hardness and wear properties. Moreover, the effect of TiC cored wire and nitrogen atmosphere as essential parameters for composite coatings preparation on the titanium substrate have been investigated ${ }^{24}$. Considering the advantages above-mentioned, index specimen was the titanium surface cladded with Ti wires by TIG method.

\section{Experimental Procedure}

\subsection{Raw materials}

Titanium medical grade 1 - UNS R50250 (supplied by Hermith $\mathrm{GmbH}$ ) was selected as the substrate with dimensions of $100 \times 100 \times 3 \mathrm{~mm}$ pieces. The surface of samples were cleaned with an ultrasonic cleaner prior surface processing 
and then, washed thoroughly with acetone to remove any dust particles and surface contaminants. The hardness of this material is $321 \mathrm{HV}$ and chemical composition shows in Table 1.

\subsection{Cored wire preparation}

Ti-base cored wires were prepared by using Ti-strip (supplied by Hermith $\mathrm{GmbH}$ ) to wrap powder of TiC by using wire drawing method. TiC packed to cored wires of $4 \mathrm{~mm}$ diameter using the Ti foil of $0.5 \mathrm{~mm}$ thickness. For this purpose, a strip of Ti with dimensions of $1300 \mathrm{~mm} \times 12 \mathrm{~mm} \times 0.5 \mathrm{~mm}$ was annealed in $760^{\circ} \mathrm{C}$ for $2 \mathrm{~h}$. Then, the strip was passed through different dies size with $6.5 \mathrm{~mm}, 6.1 \mathrm{~mm}, 5 \mathrm{~mm}$, $4.5 \mathrm{~mm}, 4.3 \mathrm{~mm}$ and $4.1 \mathrm{~mm}$ diameters, respectively. After passing the first die, the strip formed U-shape configuration. The titanium carbide powders with $20 \mu \mathrm{m}$ particle size were added to the U-shaped strip at the $6.1 \mathrm{~mm}$ die size passing process. The last pass (final stage) was done to tie up the wire, ultimately. Fig.1 illustrates three main steps of this process briefly.

\subsection{TIG cladding prosing}

Cladding prosing was conducted using single pass TIG torch traversing the substrate to produce a series of samples. The cladding parameters were pure argon and $95 \%$ argon $+5 \%$ nitrogen flow rate of $8 \mathrm{~L} \cdot \mathrm{min}^{-1}$ as shielding gas, non consumable electrode with $2.4 \mathrm{~mm}$ diameter, DC electrode negative (DCEN) supply operation current about $160 \mathrm{~A}$, electric voltage of $15 \mathrm{~V}$, and welding travel speeds of $2 \mathrm{~mm} . \mathrm{s}^{-1}$. Table 2 shows different condition and used wires as effective cladding parameters for producing various cladding samples. The samples were cut transversely to the TIG composite cladding coating and the resulting surfaces were grounded and then polished in sequences and cleaned with distilled water. The polished samples were etched with Kroll solution ${ }^{3}$.

\subsection{Coatings characterization}

The phase's analysis of composite on the top of coatings was done by $\mathrm{X}$-ray diffraction (XRD) using $\mathrm{CuK} \alpha$ generated at $40 \mathrm{kV}$ and $30 \mathrm{~mA}$ as the radiation source. Different composite coatings cross section were observed by using optical microscopy (OM) and scanning electron microscopes (SEM) equipped with an Energy Dispersive Optical Spectrometry (EDS). Moreover, dilution parameter (D) of the coatings was calculated using a metallographic method that was done by measuring the individual cross-sectional areas of the deposited filler metal and melted base metal. The ratio of the melted base metal (B) to the total melted

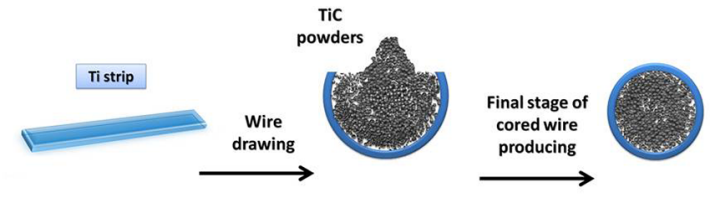

Figure 1. Schematic principle of three main steps of cored wire preparation procedure

cross-sectional area from the filler metal and the base metal $(\mathrm{A}+\mathrm{B})$ is an estimate of dilution level ${ }^{25,26}$ :

$$
D=B /(A+B)
$$

The microhardness of coating was measured along the cross-section depth of the line which started from the surface of the coatings to the base metal composite coatings. The indentation process was performed using a microhardness tester with a Vickers indenter and applying a $50 \mathrm{~g}$ load for $10 \mathrm{~s}$.

To evaluate the wear resistance of the specimens, pin-on-disc test was carried out. The used material was a cermet containing $94 \mathrm{wt} \% \mathrm{WC}$ and $6 \mathrm{wt} \%$ Co with hardness and diameter of 2300 Vickers and $30 \mathrm{~mm}$, respectively that synthesized using spark plasma sintering method. The prepared samples were machined to pin with the diameter $5 \mathrm{~mm}$. The wear experiments were carried out without lubricant, normal atmosphere conditions and at the room temperature and dry conditions. The wear conditions were a normal load of $30 \mathrm{~N}$, a sliding speed of $0.07 \mathrm{~m} . \mathrm{s}^{-1}$ and a sliding distance of 1000 $\mathrm{m}$ and weighed to precision of $0.1 \mathrm{mg}$. After each $100 \mathrm{~m}$, the pins were weighed to the same precision and the weight changes were assumed as wear weight loss.

\section{Results and Discussion}

\subsection{XRD analysis}

The XRD pattern of A1TiCL160, N1TiL160, N1TiCL160 and A1TiL160 composite coatings are shown in Fig. 2. The patterns of A1TiCL160 sample shows presence of $\mathrm{Ti}$ and $\mathrm{TiC}$ crystalline phases. In the case of N1TiL160 and N1TiCL160; TiN phase was observed as reaction product of Ti with nitrogen shielding gas.

\subsection{Microstructure}

Fig. 3 compares the macroscopic transverse crosssection views of A1TiCL160, N1TiL160, N1TiCL160 and A1TiL160 composite coatings taken by OM. The heat input values of all coatings are the same. The appropriate values of parameters have been selected to obtain homogeneous

Table 1. Chemical composition of Titanium substrate

\begin{tabular}{lccccccc}
\hline Ti & Fe & $\mathrm{N}$ & $\mathrm{O}$ & $\mathrm{H}$ & $\mathrm{C}$ & Residual, each & Residual, total \\
\hline Balance & $\leq 0.20$ & $\leq 0.03$ & $\leq 0.18$ & $\leq 0.015$ & $\leq 0.08$ & $\leq 0.1$ & $\leq 0.4$ \\
\hline
\end{tabular}


Table 2. Coding of different composite coatings

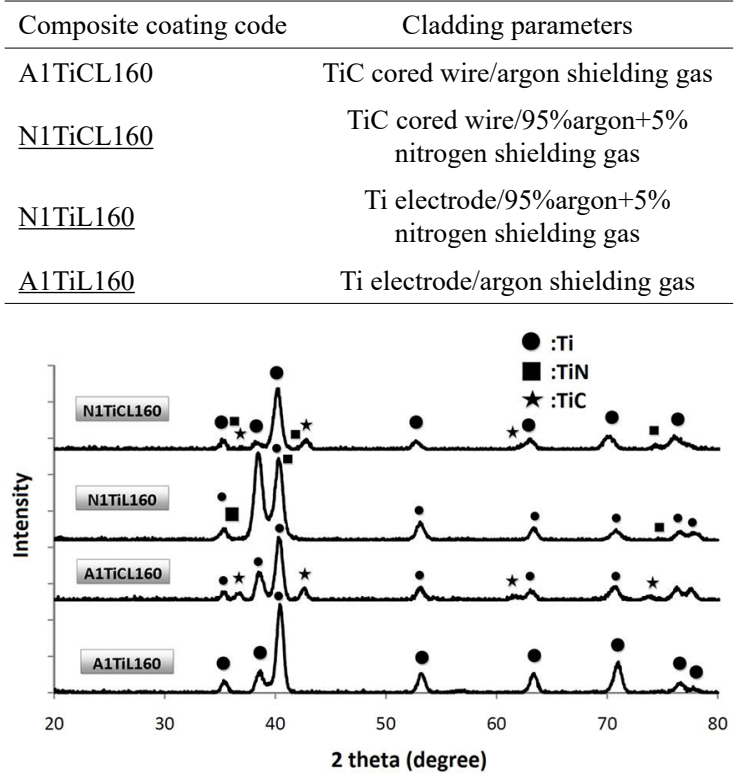

Figure 2. X-ray diffraction pattern of A1TiCL160, N1TiL160, N1TiCL160 and A1TiL160 composite coatings
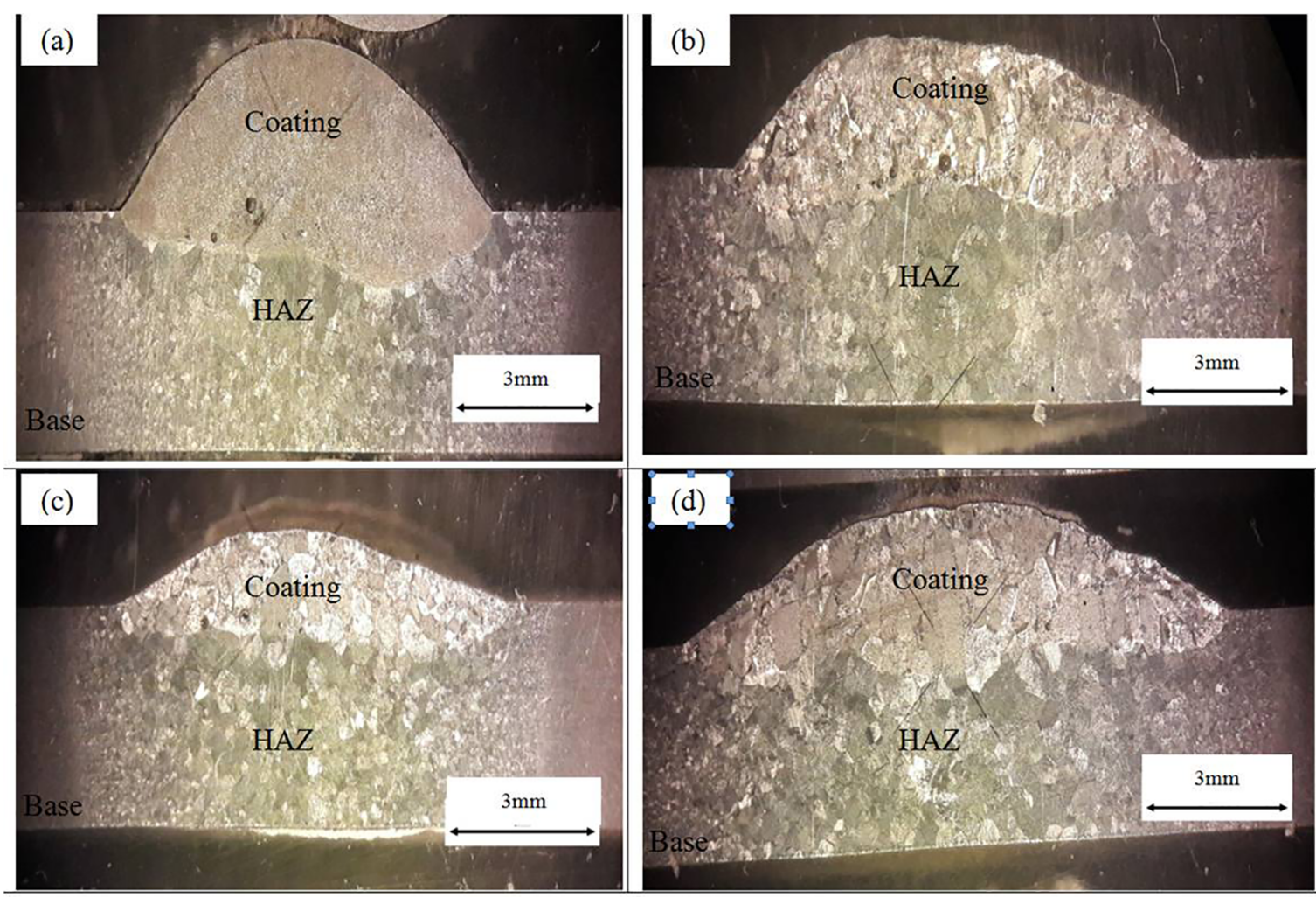

(a) AlTiCL160

(c) AlTiL160 surface. The dilution values for different composite coating were estimated using the equation (1) and are reported in Table 3.

The HAZ was formed because of rapid solidification and cooling gradient from the melted region to the substrate. A cross-sectional view of the coating could be divided into 3 regions: the cladding zone $(\mathrm{CZ})$, heat affected zone of the substrate (HAZ), and substrate. TiC with different kinds of morphologies can be formed in CZ, less ones in HAZ and seldom in the substrate. Fig. 4 reveals the microstructures of the interfaces of substrate/HAZ of different composite coatings. During coating process, the temperature of the substrate increased to melting point and martensite $\alpha$-Ti was formed in the HAZ due to the rapid solidification of the substrate by $\beta$-Ti/ $\alpha$-Ti transition.

The microstructures of the A1TiCL160 coating mainly was consist of spherical and dendritic TiC particles in a martensitic matrix. On the other hand, SEM images of A1TiL160, N1TiL160 and N1TiCL160 coatings demonstrated martensitic structure.

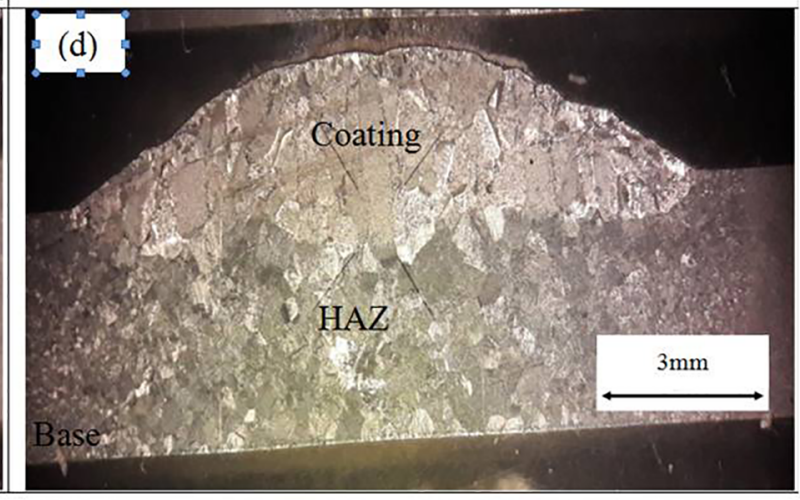

(b) N1TiCL160

(d) N1TiL160

Figure 3. Macroscopic transverse cross-section views of A1TiCL160, N1TiL160, N1TiCL160 and A1TiL160 composite coatings 
Table 3. . Dilution of different composite coatings

\begin{tabular}{lc}
\hline Composite coating code & Dilution (\%) \\
\hline A1TiCL160 & 30 \\
$\underline{\text { N1TiCL160 }}$ & 30 \\
$\underline{\text { N1TiL160 }}$ & 31 \\
A1TiL160 & 51 \\
\hline
\end{tabular}

In the molten pool, due to the low solubility of carbon in $\beta$-Ti, TiC particles were formed throughout temperature gradient was changed rapidly from the maximum to the minimum. At the first stage of solidification, while the carbon content of the coating was high, primary TiC was formed. Then, by reducing the amount of carbon in the coating near the eutectic value, eutectic irregular TiC particles was also formed and dispersed in Ti matrix.

In the heat affected zone A1 TiL160 coating, the shape of the needle-like beads is reduced by the passage of the weld area to the underlying layer, and the distance between the needlelike arms is less than that of the welded region. Moreover, the N1TiL160 coating showed a pinhole microstructure with rough and collapsed arms. The presence of nitrogen gas in the melt leads to the formation of TiN and larger dendritic arms during the solidification process, which can be helpful to improve hardness.

In the case of N1TiCL160 coating, the needle-like structure, spherical and dendrites are related to the titanium carbide and titanium nitride phases with almost titanium enriched area.

To detect the chemical composition of the dendrites formed in the microstructure, linear EDX analysis was performed from around formed dendrites. Figure 5 showed that the concentration of carbon in the dendrites is high and it can be observed that the high content of titanium carbide in the center of dendrites, while at the boundaries of dendrites, due to carbon offset, the titanium carbide concentration moved to higher amounts. The map analysis in Figure 6 also shows that the concentration of carbon in the dendrites is more than other areas.

Figs. 7 and 8 showed N1TiCL160 and N1TiL160 elemental map analysis. It can be seen, the concentration of carbon and nitrogen in the dendrites is high which confirmed formation TiC and TiN compounds. According to XRD patterns and EDS analyzes, dendrites are a mixture of different titanium based nitride and carbides along sides of titanium which normally formed dendrite structures. It seems that titanium is also present around dendrites with spherical particles. Nitrides are formed at the onset of solidification and at high temperatures.

\subsection{Microhardness}

The microhardness profiles distance from the top of the A1TiCL160, N1TiL160, N1TiCL160 and A1TiL160 composite coatings are shown in Fig. 9.
From Fig.9, it can be observed that the maximum microhardness value of the coatings was $571 \mathrm{HV}$ and the minimum value of the profile for all samples was about $321 \mathrm{HV}$. Cladding slightly improved the hardness of the HAZ due to martensitic structure formation. Also, it was found that the microhardness of the N1TiCL160 coating was higher than other coatings which was mainly attributed to TiN in-situ formation and $\mathrm{TiC}$ homogenous distribution on the top surface of the coating as TiN and TiC were very hard and plays the major role for the improvement of hardness. Low solubility of carbon in Ti pushed carbon at forehead of the solidification and due to rapid solidification led to a higher formation of TiC particles in the middle parts of the coatings. It can be concluded that presence of $\mathrm{TiC}$ and $\mathrm{TiN}$ particulates has a significant improvement in the hardness of the composite coating.

The microhardness values reached to their maximum at the transition zone. This was mainly regarded to the occurrence that is deterministic in the melting during the solidification of metal.

\subsection{Wear assessment}

The wear weight loss data of the A1TiCL160, N1TiL160, N1TiCL160 and A1TiL160 composite coatings are presented in Fig. 10. The A1 TiCL160 composite coating had a lower weight loss than the other composite coating due to the presence of fine and hard $\mathrm{TiC}$ particles in the flexible titanium alloy with uniform distribution, which plays a major role in the high resistance of a composite coating to abrasion. Generally, the matrix and hard particles have different roles. It is assumed that the wear process proceeds by preferentially abrading the matrix and pick and dig up the matrix progressively.

Moreover, titanium matrix will increase its hardness due to the frictional heat caused extremely high local temperature. Simultaneously, it caused to the extremely high affinity of titanium to adhesion of the matrix materials to the slip ring surface.

The wear in the case of metals depends on the substrate and hard particles. Presence of TiC hard particles provide a barrier against indentation, grooving and cutting of abrasive in the substrate reduced the weight loss during wear. But if TiC hard particles segregated from the substrate, it could strengthen the wear process. Thus, fracture toughness of both components and the bond between them are significant parameters in the resistance of material against wear.

The more substrate toughness caused the less scrub abrasive particles from substrate. In the A1TiCL160 composite coating substrate was toughened enough; so the abrasive particles remain in the underlying structure. But in the case of N1TiL160 and N1TiCL160 coatings, due to the presence of TiN in the substrate, the toughness reduced and the chance of the $\mathrm{TiC}$ hard particles dropping out is became high. Furthermore, these hard particles could 


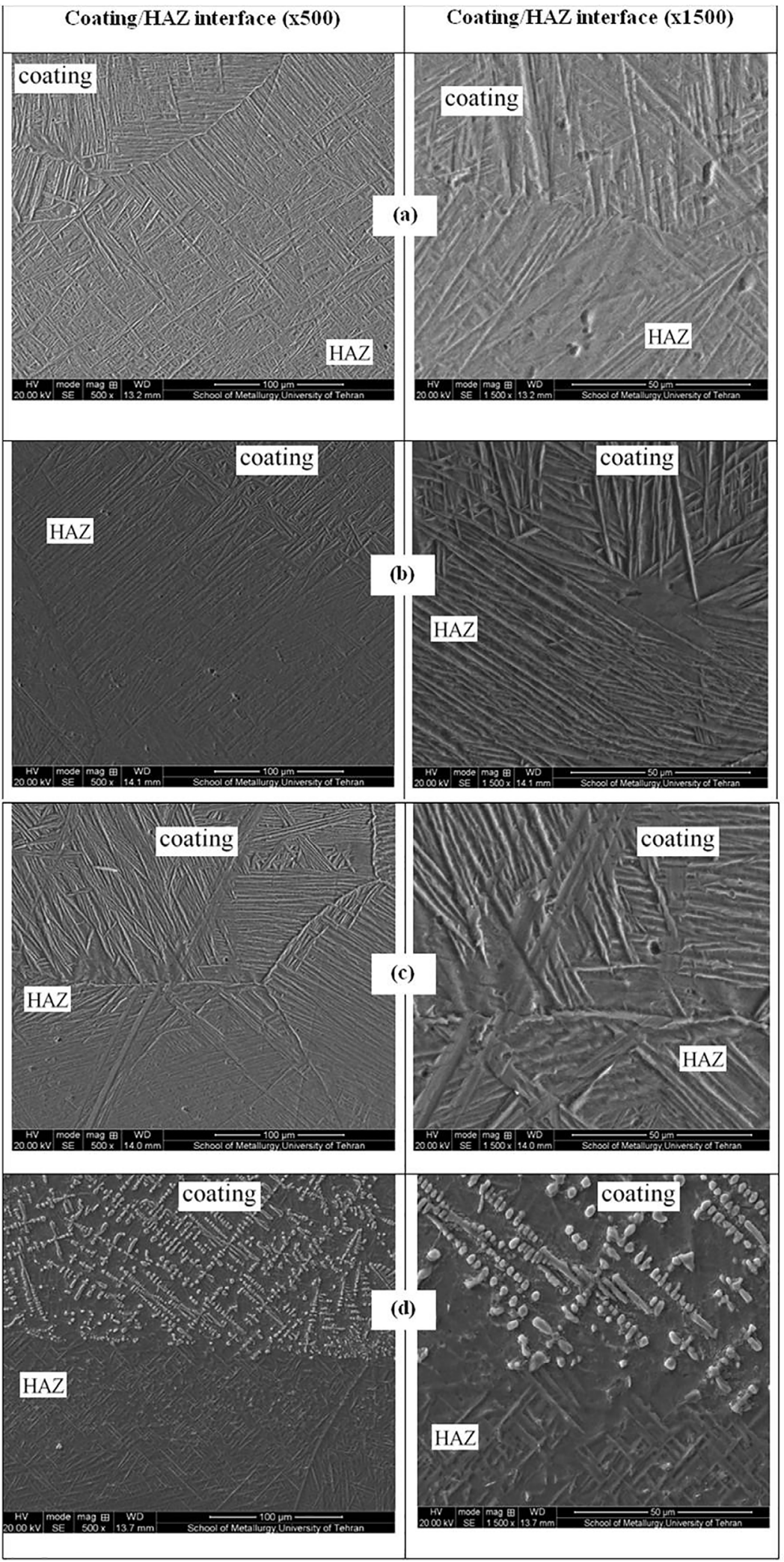
(a) AlTiL160
(b) N1TiL160
(c) N1TiCL160
(d) AlTiCL160

Figure 4. SEM micrographs of transverse cross-section views of A1TiCL160, N1TiL160, N1TiCL160 and A1TiL160 interface between HAZ and coating 


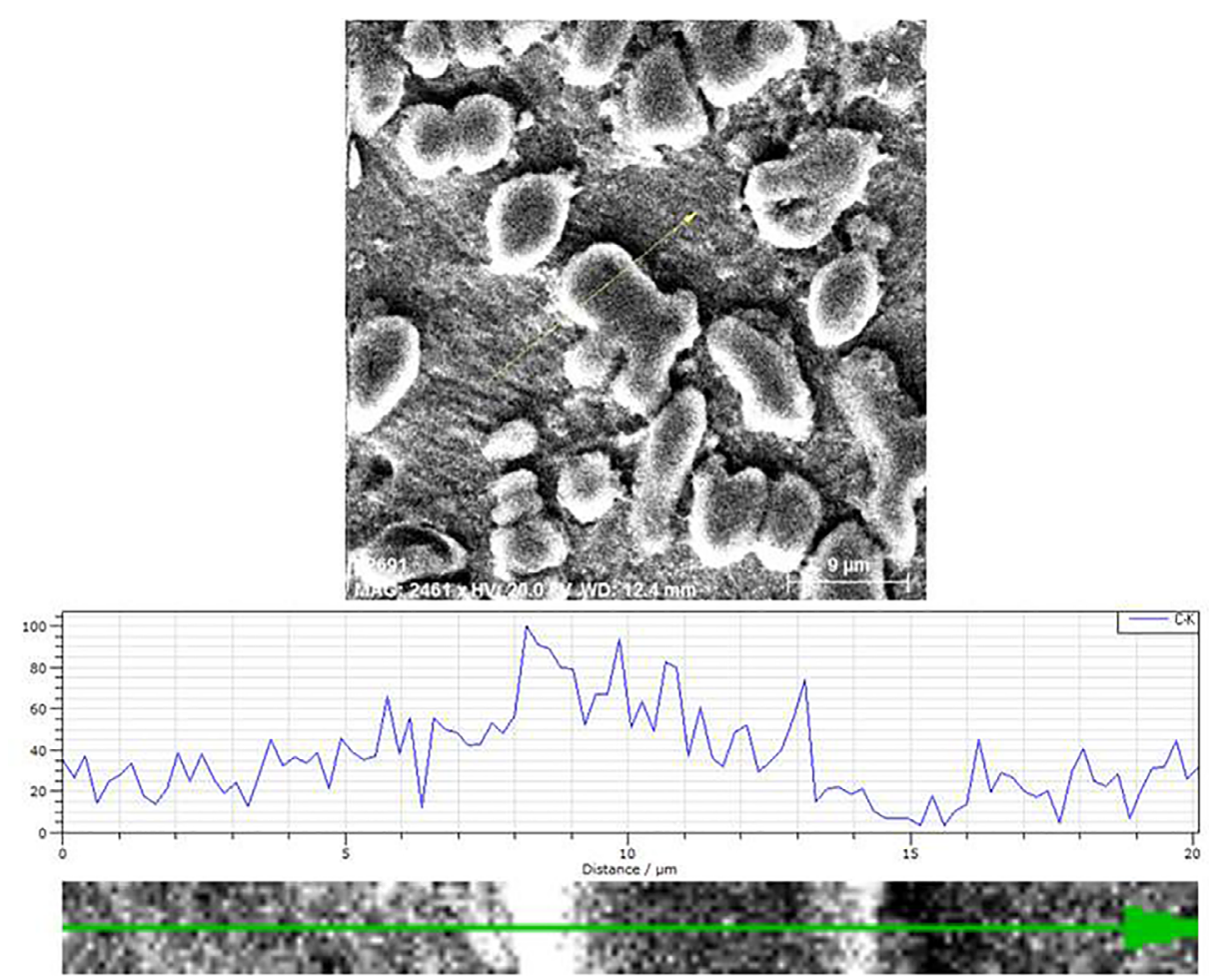

Figure 5. Linear EDX analysis of the A1TiCL160coating.
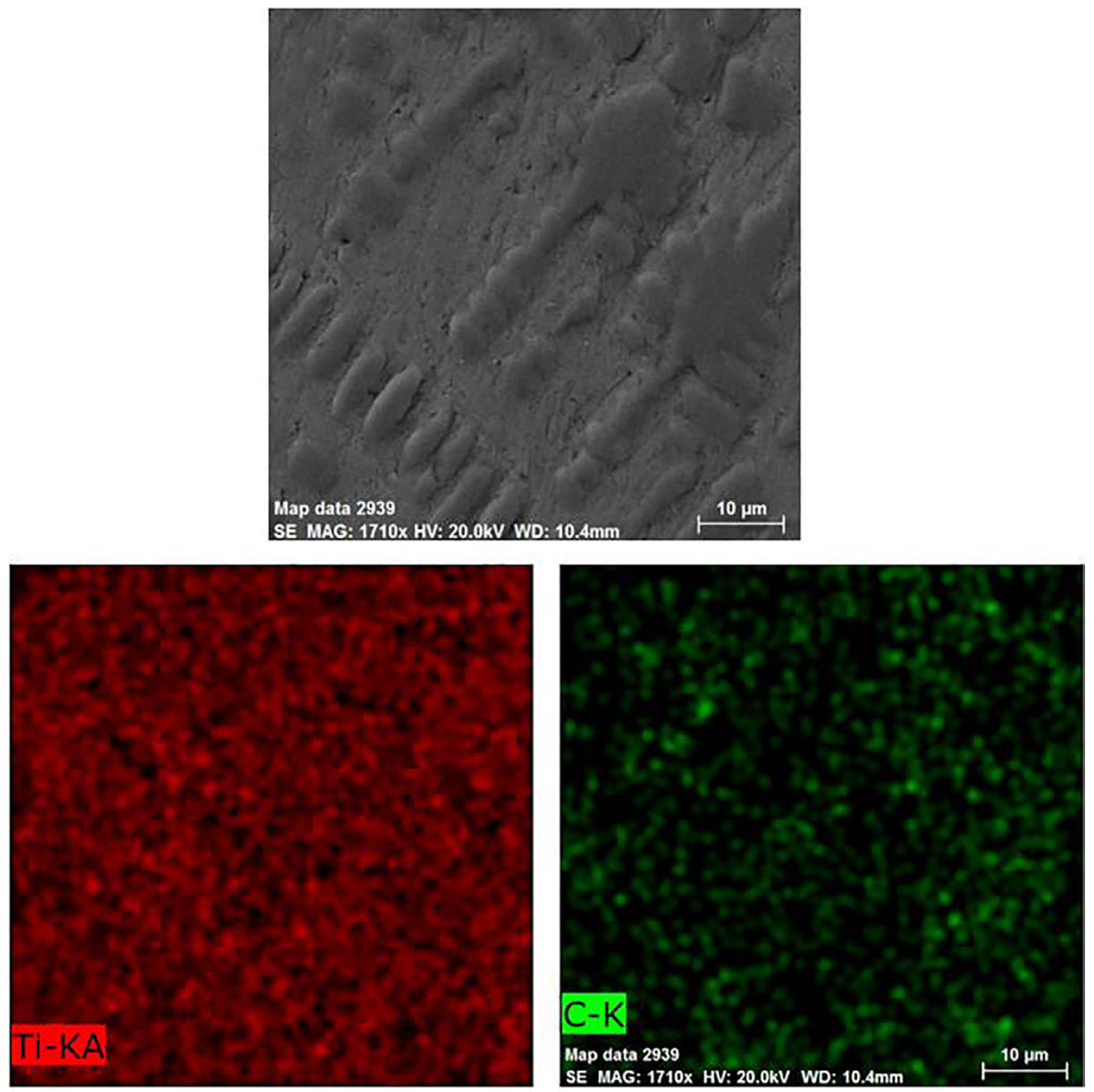

Figure 6. Map analysis of A1TiCL160 coating 


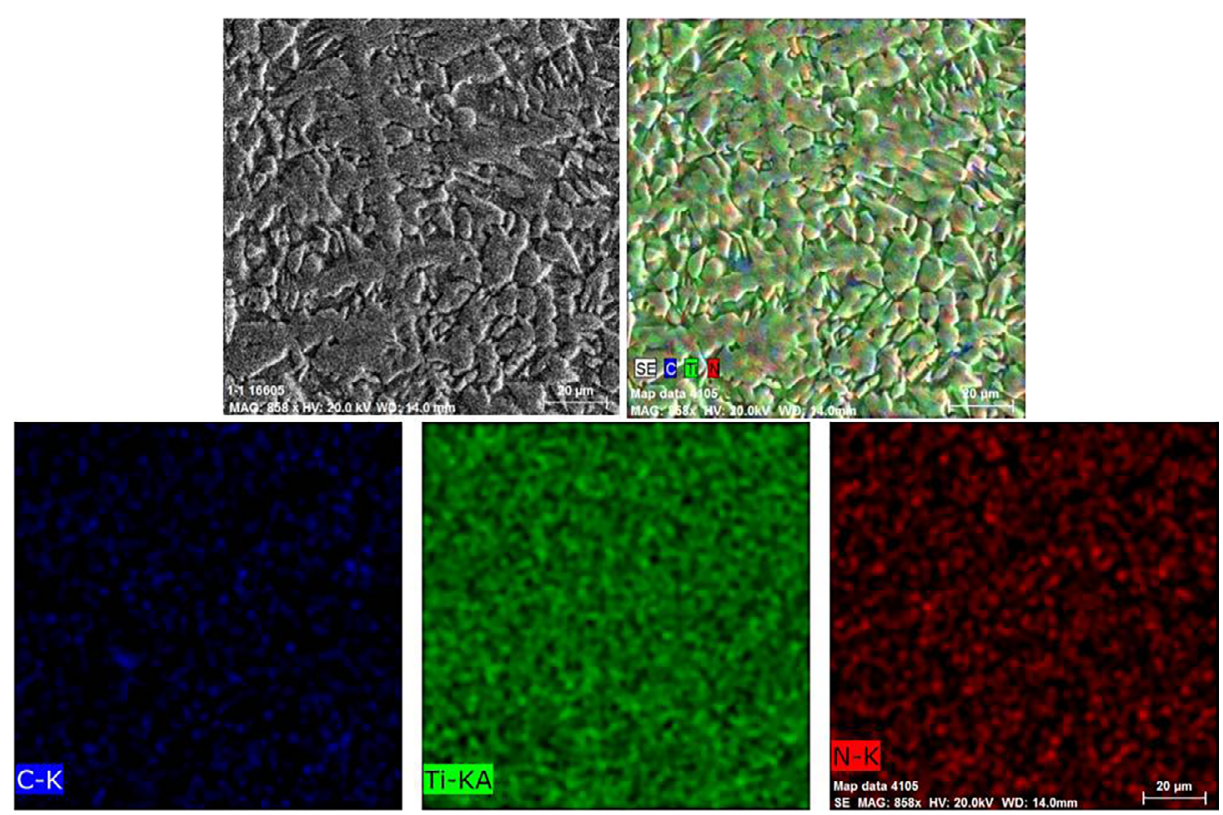

Figure 7. Map analysis of N1TiCL160 coating.
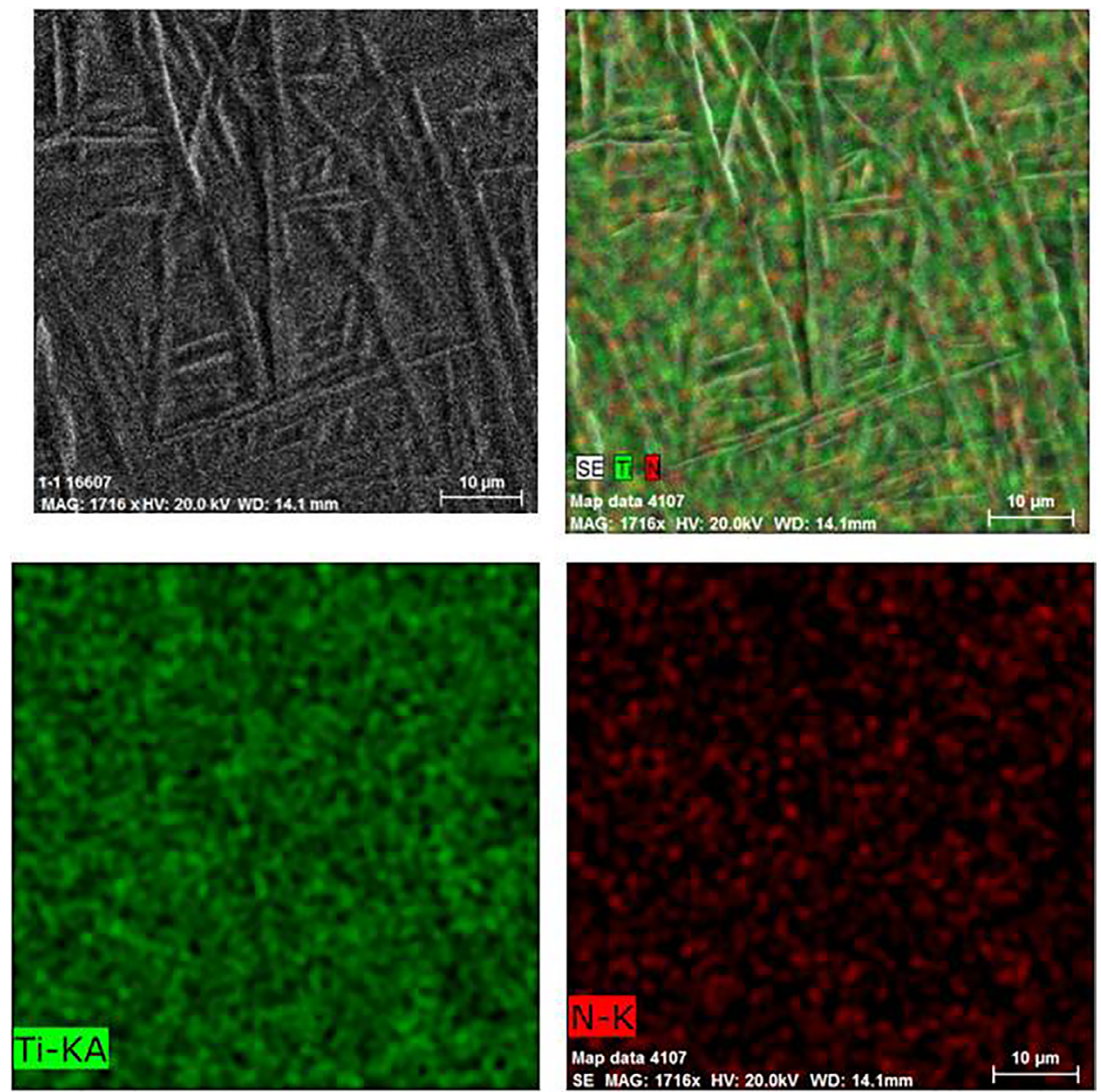

Figure 8. Map analysis of N1TiL160 coating. 


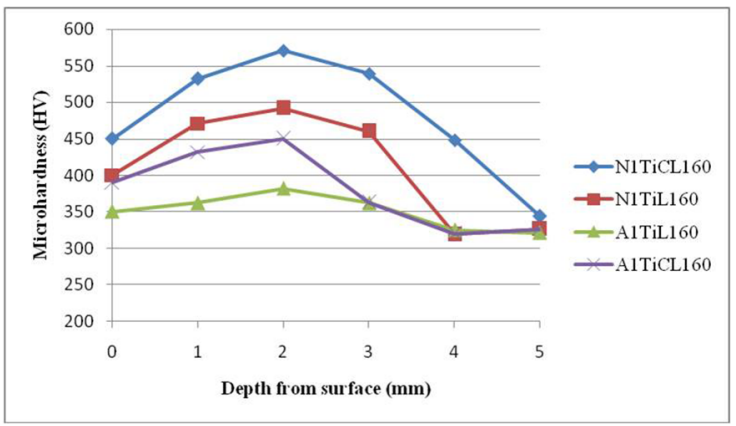

Figure 9. Microhardness versus depth of the A1TiCL160, N1 TiL160, N1TiCL160 and A1TiL160 composite coatings.

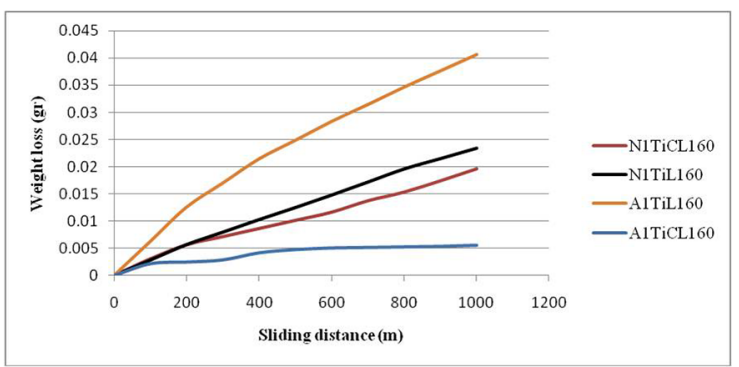

Figure 10. Wear weight loss of the A1TiCL160, N1TiL160, N1TiCL160 and A1TiL160 composite coatings as a function of sliding distance

easily penetrate into the surface of titanium substrate due to its lower microhardness and this caused serious microcutting and a greater amount of weight loss in comparison of A1TiCL160 composite coating

\section{Conclusions}

The considerable conclusions of the studies on wear properties of Ti/TiC/TiN coating on the Ti substrate prepared by TIG method at nitrogen atmosphere are as follows:

- $\quad \mathrm{TiC}$ and TiN can be formed by TIG cladding on the surface successfully with powder-filled cored wires though nitrogen as shielding gas.

- The XRD results showed that the compounds were consisted of TiC, TiN and Ti phases.

- The microstructures of the A1TiCL160 coating mainly was composed of spherical and dendrite TiC particles in a martensitic matrix.

- In the heat affected zone of A1TiL160 coating, the shape of the needle-like beads is reduced by the passage of the weld area to the underlying layer.

- N1TiL160 coating showed a pinhole microstructure with rough and collapsed arms.

- In the N1TiCL160 coating, the needle-like structure, spherical and dendrites are related to the titanium carbide and titanium nitride phases rounds enriched titanium area.

- The maximum microhardness value of the coatings was $571 \mathrm{HV}$. It was found that the microhardness of the N1TiCL160 coating was higher than other coatings.

- The A1TiCL160 composite coating had a higher wear resistance than the other composite coating due to the presence of fine and hard $\mathrm{TiC}$ particles in the flexible titanium alloy with uniform distribution.

\section{References}

1. Destefani JD. Introduction to Titanium and Titanium Alloys. In: ASM Handbook Committee. Properties and Selection: Nonferrous Alloys and Special-Purpose Materials. Materials Park: ASM International; 1990. p. 586-591.

2. Wang SH, Wei MD, Tsay LW. Tensile properties of LBW welds in Ti-6Al-4V alloy at evaluated temperatures below $450 \mathrm{C}$. Materials Letters. 2003;57(12):1815-1823.

3. Yang R, Liu Z, Yang G, Wang Y. Study of In-situ Synthesis TiCp/ Ti Composite Coating on Alloy Ti6Al4 V by TIG Cladding. Procedia Engineering. 2012;36:349-354. DOI: https://doi. org/10.1016/j.proeng.2012.03.051

4. Qu J, Blau PJ, Watkins TR, Cavin OB, Kulkarni NS. Friction and wear of titanium alloys sliding against metal, polymer, and ceramic counterfaces. Wear. 2005;258(9):1348-1356.

5. Hager CH Jr., Sanders JH, Sharma S. Unlubricated gross slip fretting wear of metallic plasma-sprayed coatings for Ti6Al4V surfaces. Wear. 2008;265(3-4):439-451. DOI: https://doi. org/10.1016/j.wear.2007.11.026

6. Heinrich G, Grögler T, Rosiwal SM, Singer RF. CVD diamond coated titanium alloys for biomedical and aerospace applications. Surface and Coatings Technology. 1997;94-95:514-520.

7. Grögler T, Zeiler E, Franz A, Plewa O, Rosiwal SM, Singer RF. Erosion resistance of CVD diamond-coated titanium alloy for aerospace applications. Surface and Coatings Technology. 1999;112(1-3):129-132.

8. Jawaid A, Sharif S, Koksal S. Evaluation of wear mechanisms of coated carbide tools when face milling titanium alloy. Journal of Materials Processing Technology. 2000;99(1-3):266-274.

9. Cai F, Zhou C, Wang N, Gong S, Xu H. Wear behavior of lowpressure plasma-sprayed $\mathrm{AlCuFe}$ quasicrystalline coating on titanium alloy. Vacuum. 2006;81(1):85-90.

10. Blau PJ, Jolly BC, Qu J, Peter WH, Blue CA. Tribological investigation of titanium-based materials for brakes. Wear. 2007;263(7-12):1202-1211.

11. Liu X, Poon RWY, Kwok SCH, Chu PK, Ding C. Plasma surface modification of titanium for hard tissue replacements. Surface and Coatings Technology. 2004;186(1-2):227-233.

12. Richard C, Kowandy C, Landoulsi J, Geetha M, Ramasawmy $\mathrm{H}$. Corrosion and wear behavior of thermally sprayed nano ceramic coatings on commercially pure Titanium and Ti-13Nb$13 \mathrm{Zr}$ substrates. International Journal of Refractory Metals and Hard Materials. 2010;28(1):115-123.

13. Tian YS, Chen CZ, Chen LX, Huo QH. Microstructures and wear properties of composite coatings produced by laser alloying of Ti-6Al-4V with graphite and silicon mixed powders. Materials Letters. 2006;60(1):109-113. 
14. Majumdar JD, Mordike BL, Manna I. Friction and wear behavior of Ti following laser surface alloying with $\mathrm{Si}, \mathrm{Al}$ and $\mathrm{Si}+\mathrm{Al}$. Wear. 2000;242(1-2):18-27.

15. Du B, Zou Z, Wang X, Li Q. In situ synthesis of Tic-Tib reinforced $\mathrm{FeCrSiB}$ composite coating by laser cladding. Surface Review and Letters. 2007;14(2):315-319.

16. Oh JC, Lee S. Correlation of microstructure with hardness and fracture properties of ( $\mathrm{TiC}, \mathrm{SiC}) / \mathrm{Ti}-6 \mathrm{Al}-4 \mathrm{~V}$ surface composites fabricated by high-energy electron-beam irradiation. Surface and Coatings Technology. 2004;179(2-3):340-348.

17. Euh K, Lee J, Lee S, Koo Y, Kim NJ. Microstructural modification and hardness improvement in boride/Ti-6Al-4V surface-alloyed materials fabricated by high-energy electron beam irradiation. Scripta Materialia. 2001;45(1):1-6.

18. Oh JC, Euh K, Lee S, Koo Y, Kim NJ. Hardness improvement of TiB2/Ti surface-alloyed material fabricated by high-energy electron beam irradiation. Scripta Materialia. 1998;39(10):13891394.

19. Wu X, Chen G. Microstructural characteristics and wear properlies of in situ formed tic particle reinforced coatings by laser cladding. Acta Metallurgica Sinica. 1988;34(12):12841288 .
20. Yu HL, Zhang W, Wang HM, Ji XC, Song ZY, Li XY, et al. In-situ synthesis of TiC/Ti composite coating by high frequency induction cladding. Journal of Alloys and Compounds. 2017;701:244-255.

21. Li BH, Liu Y, He L, Cao H, Gao SJ, Li J. Fabrication of in situ TiB2 reinforced steel matrix composite by vacuum induction melting and its microstructure and tensile properties. International Journal of Cast Metals Research. 2010;23(4):211-215.

22. Meng J, Ji Z. Microstructure and technology research of in-situ synthesis TiN-TiB2/Ni composite coating by argon arc cladding. Physics Procedia. 2013;50:253-260.

23. Yamamoto RM, Allen K, Allmon R, Alviso K, Bhachu B, Boley C, et al. A Solid State Laser for the Battlefield. In: 25th Army Science Conference; 2006 Nov 27-30; Orlando, FL, USA.

24. Zhan L, Shen P, Jiang QC. Effect of Bn/Ti Ratio on the Reaction Synthesis of Tib ${ }_{2}$ Tin $_{\mathrm{x}}$ Ceramics. International Journal of Modern Physics B. 2009;23(6-7):1172-1178.

25. Dupont JN, Banovic SW, Marder AR. Microstructural evolution and weldability of dissimilar welds between a super austenitic stainless steel and nickel-based alloys. Welding Journal. 82(6):125S-135S.

26. MonfaredA, Kokabi AH, Asgari S. Microstructural studies and wear assessments of Ti/TiC surface composite coatings on commercial pure Ti produced by titanium cored wires and TIG process. Materials Chemistry and Physics. 2013;137(3):959-966. 